\title{
PSYCHOLOGICAL FEATURES ASSOCIATED WITH GALLSTONE DISEASE
}

\author{
Dorin Dragos, ${ }^{1}$ Maria D. Tanasescu ${ }^{1}$, Mihai O. Comsa ${ }^{1}$, Alexandru Minca ${ }^{1}$, Dan Olteanu ${ }^{2}$ \\ ${ }^{I}$ Nephrology Department, Bucharest Emergency University Hospital, \\ „Carol Davila“ University of Medicine and Pharmacy, Bucharest \\ ${ }^{2} 1^{\text {st }}$ Internal Medicine Department, Bucharest Emergency University Hospital, \\ „Carol Davila“ University of Medicine and Pharmacy, Bucharest
}

\begin{abstract}
The present study aims to identify and compare the psychological factors that may contribute to an individual's predisposition for developing gallstone disease. Totally, 10,192 respondents to our specially designed triple questionnaire containing 614 psychological and medical items to assess the psychological features associated with gallstone disease were included in this cross-sectional study. The psychological items most strongly correlated with gallstone disease were those reflecting the tendency to self-sacrifice, hard-work, care for others, responsibility and discontent. At the heart of the gallstone-associated mindset seems to reside the inclination to frustrate one's desires/interests for the sake of fulfilling one's familial/social/professional duties/responsibilities.
\end{abstract}

Keywords: gallstone, psychological, psychic, self-sacrifice, hard-working, altruism, responsibility, discontent

\section{INTRODUCTION}

Despite the increased prevalence of gallstone disease (GD) and extensive research of its determinism by medical factors, there are very few reports regarding the role of psychic factors in its aetiology. At present, relevant clinical evidence suggests a role of psychological factors in the aetiology of a variety of diseases with a major in the population, independent of the geographical factors, religion or other variables of the environment that differ in large populational groups. Cardiovascular disease (CVD), for example, comprises depression and anxiety between its risk factors (Khayyam-Nekouei et al., 2013), and other reports have added to the previous the anger suppression, and stress associated with relationships or family responsibilities as determinants of CVD (Low et al., 2010). The literature has included these intricate relationships between pathologies and psychosomatic features in the field of the psychosomatic medicine. Promoting an integrative approach, psy- chosomatic medicine deals with psychophysiologic disorders in which there are demonstrable anatomic and functional changes in which psychopathologic processes are considered to be etiologically important as in the case of bronchial asthma, atrial fibrillation, essential arterial hypertension, dyspepsia, irritable bowel syndrome, peptic ulcer, hyperthyroidism, diabetes mellitus, chronic pain, migraine, rheumatoid arthritis, atopic dermatitis, chronic urticaria and pollakiuria (Jakovljević et al., 2010).

A rather old paper asserts the importance of psychological stress and of neurovegetative lability in the formation of gallstones, while suggesting an allergic type ,angioneurotic reaction" as the mediator of this process (Soustek and Dyrhonová, 1981). Emotional lability, aggressiveness, and depression proneness are psychological features more often encountered in individuals developing gallstones (Geissler, 1981). In this contest it is not uncommon however, to find a significant relationship between emotional lability, as a psychologic factor, and general disease vulnerability (Yousfi et al., 2004). Re- 
cent stress is a risk factor for GD, but it might not be an independent one, as its influence could be explained by the presence of increased levels of blood cholesterol (Sachdeva et al., 2011; Kuta et al., 1984).

Experiments performed on animals have revealed that individuals compelled to a subordination attitude are prone to bile retention, which may be a harbinger of cholesterol gallstones (Earley et al., 2004). Other types of stress (beside social stress) are also able to promote cholestasis by inhibiting gallbladder contraction, an effect attributed to the sympathetic activation induced by the corticotropin-releasing factor (CRF) (Lenz et al., 1992).

Psychic factors also seem to function as modulators for the gallstones-induced symptoms, pain being more prominent in the individuals with faulty coping abilities (Svebak et al., 2000).

The psychological features found to be associated with gallstones in the very few previous studies are too broad to delineate a profile for GD individuals. The explanation probably relates to the questionnaires currently used for psychological investigation, as the issues they are exploring (such as anxiety, depression, hostility, etc.) are too general - consequently, the associations they are revealing lack specificity. In these circumstances, a more detailed approach is needed. Therefore, we have built a triple questionnaire (Dragoş et al., 2011; Dragoş et al., 2011) out of the items that a previously conducted retrospective study (Dragoş et al., 2010) has suggested as the most susceptible to be associated with some common diseases. Using this questionnaire, we have initiated a crosssectional study aiming to ascertain whether some of the most frequent disorders are (more or less) specifically associated with certain psychological configurations. In the present paper, we present the results regarding GD in association with psychological factors.

\section{SUBJECTS AND METHODS}

\section{The study sample}

The analysis includes the answers provided by our first 10192 respondents (1711 males and 8481 females) from October 2009 until July 2011. The average age of the respondents was $33.98 \pm 11.39$ yrs $(35.43 \pm 12.52 \mathrm{yrs}$ for males, $33.68 \pm 11.13 \mathrm{yrs}$ for females). Only individuals who correctly and completely filled in our questionnaire were admitted in our study sample. The vast majority of our respondents were aged between 16 and 78 yrs (only 20 , i.e. $0.002 \%$, were between 10 and 15 yrs old, 11 of them being $15 \mathrm{yrs}$ old). In order to protect the privacy of our respondents, the only compulsory data were the age and gender, besides an e-mail address that was used for correspondence. As a compensation for their participation, we supplied each respondent with a psychological profile based on their responses (the method we built this psychological profile is irrelevant to the scope of the study) and an estimation of their disease risk according to the results of the study after completion. No other incentive was offered to the respondents - we considered that this was the most appropriate method to ensure that their answers were unbiased, sincere and reflecting reality. We refused to send the certificates for participation in this study as requested by two respondents, thereby discouraging anyone that would have superficially (or even randomly) filled in the questionnaire, driven by the purpose of obtaining a participation certificate. There are probably only few respondents that insincerely filled in the questionnaire, as no organization is using it as a personnel selection tool.

\section{The questionnaire}

Among the 614 items of our triple questionnaire (available at: http://drdorindragos.ro/causesdiseases.html), 533 are exploring psychological issues [these are the psychological items (PsyIts)], while the remainder refer to various symptoms and diseases (respiratory, cardiac, digestive, urinary, gynecological) [these are the medical items (MedIts)]. For each item, the respondents were asked to check one out of five variants (qualificatives) arranged in a quantitatively increasing order. One of the 81 MedIts was "I was diagnosed with gallstones on ultrasound" - but in this paper it was interpreted in relation to the psychological correlations of this MedIt. The five variants the respondent could check for this MedIt were: "Less than 3 months ago", "Less than 6 months ago", "Less than 1 year ago", "More than 1 year ago", and "Never". Corresponding to these temporal cutoff points, we have divided our patients into four pairs of dichotomous categories: those with ultrasonographic evidence of gallstones in the last 3 months (G-3M-group), in the last 6 months (G-6M-group), in the last 12 months (G-12M-group), any time in the past (G-group) and the others. Obviously, the G-group includes the G-12M-group, which includes the G-6M-group, which includes the G-3M-group. 


\section{Statistical analysis}

By systematically applying the Cronbach alpha (CrA) test at first to all the pairs of Psylts and then to various groups of Psylts, we eventually divided the PsyIts into 64 psychological categories (PsyCts) (one PsyIt may belong to several PsyCts). A CrA $>0.7$ was considered to indicate good internal consistency of a given PsyCt. Furthermore, we requested that no PsyIt in a given PsyCt lowers the CrA for the rest of the group with more than 0.02, i.e. the CrA for the group without the respective PsyIt shouldn't be more than 0.02 above the CrA for the group including that PsyIt. The fulfillment of this criterion (for which we propose the term internal synergy) indicates that no item in the group was arbitrarily added to it. We have chosen selfexplantory names for the PsyCts. We have further grouped the ensuing PsyCts into four domains: 1. Preoccupation with the basal conditions of existence (survival/fear, health/disease/death, money, lodging); 2. Interaction with other people; 3. Action, will/volition, self-assertion; 4. Preoccupation with the exterior.

In order to establish the correlation between PsyIts/PsyCts and the MedIt we have used the chisquare test (ChiSq) applied to all the pairs formed of the MedIt and a PsyIt/PsyCt. Due to the strength of our sample, there were no expected values less than five, rendering it unnecessary to apply Fisher's exact test. The correlation with an entire PsyCt was calculated by taking into account both the highest score of any PsyIt in that PsyCt, and the average score of all the PsyIts in the same PsyCt. As the results yielded by the two methods were not significantly different, we present only those obtained by means of the first. Odds ratio (OR) was used as a measure of association.

For clarity reasons we have reduced the five variants the respondent could check for each PsyIt to only two: below and above the average for the respective PsyIt (for each PsyIt we have calculated the average over the whole group of respondents after assigning numerical values -1 through 5 - to the five qualificatives).

Due to the large number of calculated parameters $(614 \times 613 / 2=188191)$, we have based our conclusions only on the results with a $\mathrm{P}<10^{-6}$ [we have considered these results as absolutely statistically significant (ASS)]. Nonetheless, for fear of sliding into Type II error, we have also mentioned some results with a $\mathrm{P}>10^{-6}$, but $<0.05$ [we have considered these results as relatively statistically significant (RSS)].
We shall rely in our conclusions on the Psylts ASS correlated (ASS-C) with the G group (ASSC_G).

The statistical analysis was done using Visual Basic for Applications built in Microsoft Excel 2000 (Redmond, WA, US).

\section{Ethics}

As our respondents were free to preserve their anonymity and were exempt from any prejudicial effects. While advertising our research we clearly stated that the information from our respondents will be used in a study. Therefore, by filling in the questionnaires, our respondents implicitly gave their informed consent thereto. Consequently, we consider that our study raises no ethical concerns.

\section{RESULTS}

Among the 10192 respondents there were 1442 that have gallstones in the present or have had sometime in the past. Therefore, our case group was 1442 strong, while the control group was 8750 strong.

\section{The psychological features of gallstone patients (results provided by the chi-squared test)}

We present first the PsyIts ASS-C_G, assembled under the PsyCts and the domains they belong to. The Psylts in the first two domains most strongly correlated with G group belong to the „Health”, „Fear”, and „Equity” PsyCts (Table 1), while those in the third domain belong to the „Work” and „Discontent" PsyCts (Table 2). The fourth domain (Table 3 ) includes some of the most consistently represented and most strongly related to G group PsyCts. The strongest correlation is provided by „Sacrifice" PsyCt, which reflects the inclination to neglect one's interests for the benefit of others. Closely connected with it are a less well represented PsyCt, "Altruism", expressing the eagerness to help others, and the best represented PsyCt, „Compassion”, defined by the worry about/sympathy for others.

In order to increase the probability that the PsyIts we are identifying are indeed related to GD, we have searched for those PsyIts that are both ASSC_G and at least RSS correlated (RSS-C) with at least one of the other three gallstone groups - we have found that the strongest correlations are yielded by the PsyIts in the first two domains expressing claustrophobia and frustration (Table 4), by those in the third domain reflecting inclination to work and discontent (Table 4), and by self-sacrifice, al- 
TABLE 1. Correlation of a selection of items in the first two domains with ultrasonographic evidence of gallstones.

\begin{tabular}{|c|c|c|c|c|c|c|c|}
\hline PsyCt & Psylt & E-D- & E-D+ & E+D- & $E+D+$ & OR $(95 \% \mathrm{Cl})$ & $P_{-}$ \\
\hline "Order" & „When I get home I start tidying up" & 6026 & 744 & 2924 & 498 & $1.38(1.22-1.56)$ & $2 \times 10^{-7}$ \\
\hline „Couple, partner" & $\begin{array}{l}\text { "I am discontented with the attitude, gestures, } \\
\text { actions, habits of my partner (spouse, friend)" }\end{array}$ & 4730 & 530 & 4220 & 712 & $1.51(1.34-1.7)$ & $2 \times 10^{-11}$ \\
\hline „Rumination” & $\begin{array}{l}\text { "It is difficult for me to fall asleep because I am } \\
\text { troubled by thoughts" }\end{array}$ & 3976 & 452 & 4974 & 790 & $1.4(1.24-1.58)$ & $9 \times 10^{-8}$ \\
\hline "Conflict" & „Conflicts/fights affect/bother me” & 2452 & 253 & 6498 & 989 & $1.48(1.28-1.71)$ & $1 \times 10^{-7}$ \\
\hline \multirow{5}{*}{ "Equity" } & "I am honest even if this puts me at a disadvantage" & 6721 & 814 & 2229 & 428 & $1.58(1.39-1.79)$ & $7 \times 10^{-13}$ \\
\hline & $\begin{array}{l}\text { "I consider that we cannot manifest ourselves } \\
\text { freely, without restrictions, but only by respecting } \\
\text { the rules of decency" }\end{array}$ & 5174 & 596 & 3776 & 646 & $1.49(1.32-1.67)$ & $6 \times 10^{-11}$ \\
\hline & "I do my best in order to preserve justice" & 2479 & 241 & 6471 & 1001 & $1.59(1.37-1.85)$ & $6 \times 10^{-10}$ \\
\hline & $\begin{array}{l}\text { "I believe that laws should be strictly applied in all } \\
\text { situations" }\end{array}$ & 4804 & 564 & 4146 & 678 & $1.39(1.24-1.57)$ & $5 \times 10^{-8}$ \\
\hline & $\begin{array}{l}\text { "I respect the laws/rules even if it's to my } \\
\text { disadvantage" }\end{array}$ & 4961 & 587 & 3989 & 655 & $1.39(1.23-1.56)$ & $6 \times 10^{-8}$ \\
\hline "Sense of injustice" & „I was unjustly punished" & 4630 & 524 & 4320 & 718 & $1.47(1.3-1.66)$ & $3 \times 10^{-10}$ \\
\hline
\end{tabular}

The selection of psychological items in the first two domains absolutely statistically significantly correlated with ultrasonographic evidence of gallstones any time in the past; PsyCt/Psylt $=$ psychological category/item; $E+D+E+D-=$ number of exposed patients with/without gallstones; $\mathrm{E}-\mathrm{D}+/ \mathrm{E}-\mathrm{D}-\mathrm{=}$ number of non-exposed patients with/without gallstones; $\mathrm{OR}=$ odds ratio; $95 \% \mathrm{Cl}=95 \%$ confidence interval; $\mathrm{P}=\mathrm{P}$-value.

TABLE 2. Correlation of the Psylts in the third domain with ultrasonographic evidence of gallstones.

\begin{tabular}{|c|c|c|c|c|c|c|c|}
\hline PsyCt & Psylt & E-D- & E-D+ & $E+D-$ & $E+D+$ & OR $(95 \% \mathrm{CI})$ & $\boldsymbol{P}_{-}$ \\
\hline \multirow{4}{*}{ „Work” } & "I tend to work excessively at home" & 6557 & 764 & 2393 & 478 & $1.71(1.52-1.94)$ & $6 \times 10^{-18}$ \\
\hline & $\begin{array}{l}\text { "I volunteer to do more than I am asked } \\
\text { to" }\end{array}$ & 5735 & 649 & 3215 & 593 & $1.63(1.45-1.84)$ & $7 \times 10^{-16}$ \\
\hline & $\begin{array}{l}\text { "I work assiduously at the workplace and/ } \\
\text { or at home" }\end{array}$ & 4503 & 479 & 4447 & 763 & $1.61(1.43-1.82)$ & $8 \times 10^{-15}$ \\
\hline & $\begin{array}{l}\text { "I tend to work excessively at my job on } \\
\text { my own initiative" }\end{array}$ & 2988 & 307 & 5962 & 935 & $1.53(1.33-1.75)$ & $9 \times 10^{-10}$ \\
\hline \multirow{2}{*}{$\begin{array}{l}\text { „Profession } \\
\text { preoccupation” }\end{array}$} & $\begin{array}{l}\text { "I am ready to make compromises to keep } \\
\text { a certain job or position” }\end{array}$ & 4462 & 740 & 4488 & 502 & $0.67(0.6-0.76)$ & $1 \times 10^{-10}$ \\
\hline & $\begin{array}{l}\text { "I am ready to compromise in order to get } \\
\text { a particular job or position" }\end{array}$ & 5513 & 862 & 3437 & 380 & $0.71(0.62-0.8)$ & $1 \times 10^{-7}$ \\
\hline $\begin{array}{l}\text { "Demanding } \\
\text { profession" }\end{array}$ & "I think I have too many tasks at work" & 4314 & 499 & 4636 & 743 & $1.39(1.23-1.57)$ & $8 \times 10^{-8}$ \\
\hline \multirow{2}{*}{ „Perfectionism” } & "I work seriously" & 5780 & 706 & 3170 & 536 & $1.38(1.23-1.56)$ & $1 \times 10^{-7}$ \\
\hline & "I consider myself fastidious in my actions" & 5548 & 674 & 3402 & 568 & $1.37(1.22-1.55)$ & $2 \times 10^{-7}$ \\
\hline "Authority" & $\begin{array}{l}\text { „I am affected/hurt by the conflict with } \\
\text { authority persons/factors (in the family, } \\
\text { group, community, profession, society, } \\
\text { institutions, authorities, police, church, } \\
\text { etc.)" }\end{array}$ & 4313 & 475 & 4637 & 767 & $1.5(1.33-1.7)$ & $5 \times 10^{-11}$ \\
\hline $\begin{array}{l}\text { „Authoritarian } \\
\text { parents" }\end{array}$ & $\begin{array}{l}\text { "My parents have forced me to behave/ } \\
\text { act in a given way" }\end{array}$ & 4929 & 587 & 4021 & 655 & $1.37(1.21-1.54)$ & $2 \times 10^{-7}$ \\
\hline „Self-assertion” & $\begin{array}{l}\text { "When I hear about the successes of } \\
\text { others, I compare them with my own" }\end{array}$ & 6391 & 784 & 2559 & 458 & $0.69(0.61-0.78)$ & $2 \times 10^{-9}$ \\
\hline \multirow{2}{*}{ "Discontent" } & „In life, I had troubles” & 4471 & 430 & 4479 & 812 & $1.89(1.67-2.14)$ & $2 \times 10^{-24}$ \\
\hline & „Life has been unfair to me" & 5062 & 577 & 3888 & 665 & $1.5(1.33-1.69)$ & $2 \times 10^{-11}$ \\
\hline
\end{tabular}

The psychological items in the third domain absolutely statistically significantly correlated with ultrasonographic evidence of gallstones any time in the past; PsyCt/Psylt = psychological category/item; $E+D+/ E+D-=$ number of exposed patients with/without gallstones; $E-D+/ E-D-=$ number of non-exposed patients with/without gallstones; $O R=$ odds ratio; $95 \% \mathrm{Cl}=95 \%$ confidence interval; $P=P$-value.

truism and compassion associated PsyIts, in the fourth domain (Table 5).

Among the PsyCts that are ASS-C or RSS-C with at least one of the four gallstone groups (Table $6)$, the strongest correlations are provided by „Sac- rifice" and "Work" PsyCts (both ASS-C_G), followed by "Authority" and "Authoritarian parents" (both ASS-C_G), and then by "Equity", "Cleanliness", and "Discontent". 
TABLE 3. The correlation of the Psylts in the fourth domain with ultrasonographic evidence of gallstones.

\begin{tabular}{|c|c|c|c|c|c|c|c|}
\hline PsyCt & Psylt & E-D- & E-D+ & $E+D-$ & $\mathrm{E}+\mathrm{D}+$ & OR $(95 \% \mathrm{Cl})$ & ${ }_{-}^{P}$ \\
\hline \multirow{6}{*}{ „Compassion” } & $\begin{array}{l}\text { "It affects me when someone is suffering/ } \\
\text { has troubles" }\end{array}$ & 3848 & 384 & 5102 & 858 & $1.69(1.48-1.91)$ & $6 \times 10^{-16}$ \\
\hline & $\begin{array}{l}\text { "I feel myself the distress/suffering of } \\
\text { others" }\end{array}$ & 5884 & 687 & 3066 & 555 & $1.55(1.37-1.75)$ & $6 \times 10^{-13}$ \\
\hline & "I worry for my family members" & 4843 & 544 & 4107 & 698 & $1.51(1.34-1.71)$ & $9 \times 10^{-12}$ \\
\hline & $\begin{array}{l}\text { "I worry for my colleagues or neighbors, } \\
\text { even if we are not close to each other" }\end{array}$ & 4584 & 525 & 4366 & 717 & $1.43(1.27-1.62)$ & $3 \times 10^{-9}$ \\
\hline & $\begin{array}{l}\text { "I worry about strangers if I know they are } \\
\text { in a difficult situation" }\end{array}$ & 3361 & 363 & 5589 & 879 & $1.46(1.28-1.66)$ & $1 \times 10^{-8}$ \\
\hline & "I worry for my partner (spouse/friend)" & 4952 & 592 & 3998 & 650 & $1.36(1.21-1.53)$ & $4 \times 10^{-7}$ \\
\hline \multirow{5}{*}{ „Sacrifice” } & $\begin{array}{l}\text { "I neglect my needs in order to take care of } \\
\text { the others" }\end{array}$ & 6476 & 734 & 2474 & 508 & $1.81(1.6-2.05)$ & $6 \times 10^{-22}$ \\
\hline & "I sacrifice myself for others" & 6427 & 752 & 2523 & 490 & $1.66(1.47-1.88)$ & $4 \times 10^{-16}$ \\
\hline & $\begin{array}{l}\text { "I consider the interests of others above my } \\
\text { own interests" }\end{array}$ & 5994 & 702 & 2956 & 540 & $1.56(1.38-1.76)$ & $4 \times 10^{-13}$ \\
\hline & $\begin{array}{l}\text { "I do my best for the comfort of others, } \\
\text { even if this makes me feel uncomfortable" }\end{array}$ & 5916 & 696 & 3034 & 546 & $1.53(1.36-1.73)$ & $3 \times 10^{-12}$ \\
\hline & "I give up my affairs to help others" & 6593 & 815 & 2357 & 427 & $1.47(1.29-1.66)$ & $2 \times 10^{-9}$ \\
\hline \multirow[b]{2}{*}{ „Altruism” } & "I do everything I can for others" & 4086 & 436 & 4864 & 806 & $1.55(1.37-1.76)$ & $2 \times 10^{-12}$ \\
\hline & $\begin{array}{l}\text { „In order to feel all right, I do something for } \\
\text { others" }\end{array}$ & 6498 & 786 & 2452 & 456 & $1.54(1.36-1.74)$ & $9 \times 10^{-12}$ \\
\hline \multirow{3}{*}{ „Responsibility” } & $\begin{array}{l}\text { „If I do not fulfill my civic duties, I feel } \\
\text { guilty" }\end{array}$ & 2940 & 298 & 6010 & 944 & $1.55(1.35-1.78)$ & $3 \times 10^{-10}$ \\
\hline & $\begin{array}{l}\text { "I was feeling guilty if I went to school with } \\
\text { unlearned lesson or neglected homework" }\end{array}$ & 4361 & 499 & 4589 & 743 & $1.41(1.25-1.6)$ & $2 \times 10^{-8}$ \\
\hline & „At school I missed classes” $(x)$ & 4473 & 518 & 4477 & 724 & $1.4(1.24-1.57)$ & $5 \times 10^{-8}$ \\
\hline \multirow{3}{*}{ „Commitment" } & $\begin{array}{l}\text { "I tend to work excessively at my job on my } \\
\text { own initiative" }\end{array}$ & 2988 & 307 & 5962 & 935 & $1.53(1.33-1.75)$ & $9 \times 10^{-10}$ \\
\hline & "I work seriously" & 5780 & 706 & 3170 & 536 & $1.38(1.23-1.56)$ & $1 \times 10^{-7}$ \\
\hline & „I put my heart in what I do” & 5387 & 652 & 3563 & 590 & $1.37(1.21-1.54)$ & $2 \times 10^{-7}$ \\
\hline
\end{tabular}

The psychological items in the fourth domain absolutely statistically significantly correlated with ultrasonographic evidence of gallstones any time in the past; PsyCt/Psylt = psychological category/item; $E+D+/ E+D-=$ number of exposed patients with/without gallstones; $E-D+/ E-D-=$ number of non-exposed patients with/without gallstones; $O R=$ odds ratio; $95 \% \mathrm{Cl}=95 \%$ confidence interval; $P=P$-value; $x=$ the opposite of that item was taken into account.

\section{The internal consistency and synergy of the PsyCts (results provided by the Cronbach alpha test)}

As stated above, CrA test was used to assess the internal consistency and synergy of the subgroups of PsyIts in each PsyCt ASS-C_G.

The CrA for the subgroup of five PsyIts in ,Equity" PsyCt ASS-C_G is insufficient (0.663). Nonetheless, the subgroup has internal synergy (i.e. none of Psylts lowers the group CrA, the corresponding CrA values for the subgroup without each of its PsyIts in turn being $0.62,0.649,0.63,0.598$, and 0.558 , respectively), while the whole „Equity” PsyCt (which includes 16 PsyIts) has both internal consistency $(\mathrm{CrA}=0.84)$ and synergy.

The CrA for the four PsyIts in ,Work” PsyCt ASS-C_G is good (0.785), proving that this PsyCt is characteristically associated with the G group.
This PsyCt has also internal synergy (the corresponding CrA values for the subgroup without each of its PsyIts in turn being $0.753,0.722,0.733$, and 0.722 , respectively).

In „Compassion” PsyCt, there is good internal consistency $(\mathrm{CrA}=0.761)$. However, internal synergy is faulty, as among the corresponding CrA values for the subgroup without each of its PsyIts in turn $(0.699,0.717,0.748,0.714,0.701$, and 0.775 , respectively), the last one lowers the group's CrA. Nevertheless, we have overcome this setback after dropping the two PsyIts referring to worry about relatives (,I worry for my family members" and „I worry for my partner"), the CrA value for the resultant four-PsyIts subgroup being 0.794, unsurpassed by none ot the CrA values for the subgroup without each of its PsyIts in turn $(0.738,0.75,0.768$, and 0.713 , respectively). 
TABLE 4. The Psylts in the first three domains absolutely or relatively significantly correlated with at least two of the four gallstone groups.

\begin{tabular}{|c|c|c|c|c|c|c|c|c|}
\hline \multirow[b]{2}{*}{ Psylt } & \multicolumn{2}{|c|}{ G-group } & \multicolumn{2}{|c|}{ G-12M-group } & \multicolumn{2}{|c|}{ G-6M-group } & \multicolumn{2}{|c|}{ G-3M-group } \\
\hline & $P$ & $\begin{array}{c}\text { OR } \\
(95 \% \mathrm{Cl})\end{array}$ & $P$ & $\begin{array}{c}\text { OR } \\
(95 \% \mathrm{Cl})\end{array}$ & $P$ & $\begin{array}{c}\text { OR } \\
(95 \% \mathrm{Cl})\end{array}$ & $P$ & $\begin{array}{c}\text { OR } \\
(95 \% \mathrm{Cl})\end{array}$ \\
\hline $\begin{array}{l}\text { ("Order”) „When I get home I start } \\
\text { tidying up" }\end{array}$ & $5 \times 10^{-08}$ & $\begin{array}{c}1.4 \\
(1.24-1.58)\end{array}$ & 0.04 & $\begin{array}{c}1.27 \\
(1.01-1.61)\end{array}$ & & & & \\
\hline $\begin{array}{l}\text { („Couple, partner") „I am } \\
\text { discontented with the attitude, } \\
\text { gestures, actions, habits of my } \\
\text { partner (spouse, friend)” }\end{array}$ & $7 \times 10^{-12}$ & $\begin{array}{c}1.52 \\
(1.35-1.71)\end{array}$ & 0.0007 & $\begin{array}{c}1.49 \\
(1.18-1.87)\end{array}$ & 0.03 & $\begin{array}{c}1.44 \\
(1.03-2.02)\end{array}$ & 0.04 & $\begin{array}{c}1.61 \\
(1.03-2.53)\end{array}$ \\
\hline $\begin{array}{l}\text { („,Rumination") „It is difficult for } \\
\text { me to fall asleep because I am } \\
\text { troubled by thoughts” }\end{array}$ & $2 \times 10^{-08}$ & $\begin{array}{c}1.42 \\
(1.26-1.61)\end{array}$ & 0.0006 & $\begin{array}{c}1.51 \\
(1.19-1.92)\end{array}$ & 0.003 & $\begin{array}{c}1.71 \\
(1.19-2.46)\end{array}$ & 0.01 & $\begin{array}{c}1.8 \\
(1.12-2.92)\end{array}$ \\
\hline $\begin{array}{l}\text { („Sense of injustice”) „I was } \\
\text { unjustly punished” }\end{array}$ & $2 \times 10^{-10}$ & $\begin{array}{c}1.47 \\
(1.31-1.66)\end{array}$ & 0.006 & $\begin{array}{c}1.38 \\
(1.1-1.74)\end{array}$ & 0.04 & $\begin{array}{c}1.42 \\
(1.01-1.99)\end{array}$ & 0.03 & $\begin{array}{c}1.62 \\
(1.03-2.55)\end{array}$ \\
\hline $\begin{array}{l}(\text { („Work") „I tend to work } \\
\text { excessively at home” }\end{array}$ & $7 \times 10^{-18}$ & $\begin{array}{c}1.71 \\
(1.51-1.94)\end{array}$ & 0.03 & $\begin{array}{c}1.3 \\
(1.02-1.66)\end{array}$ & & & & \\
\hline $\begin{array}{l}\text { („Work") „I volunteer to do more } \\
\text { than I am asked to" }\end{array}$ & $2 \times 10^{-16}$ & $\begin{array}{c}1.65 \\
(1.46-1.85)\end{array}$ & 0.002 & $\begin{array}{c}1.42 \\
(1.13-1.79)\end{array}$ & 0.01 & $\begin{array}{c}1.54 \\
(1.1-2.15)\end{array}$ & 0.003 & $\begin{array}{c}1.95 \\
(1.25-3.03)\end{array}$ \\
\hline $\begin{array}{l}\text { (,Demand. profession”) „I think I } \\
\text { have too many tasks at work” }\end{array}$ & $8 \times 10^{-08}$ & $\begin{array}{c}1.39 \\
(1.23-1.57)\end{array}$ & 0.002 & $\begin{array}{c}1.44 \\
(1.14-1.82)\end{array}$ & & & & \\
\hline $\begin{array}{l}\text { („Contemplative nat.”) „I am } \\
\text { impressed with landscapes, } \\
\text { nature, flowers” }\end{array}$ & $3 \times 10^{-09}$ & $\begin{array}{c}1.43 \\
(1.27-1.61)\end{array}$ & 0.0009 & $\begin{array}{c}1.47 \\
(1.17-1.85)\end{array}$ & 0.003 & $\begin{array}{c}1.67 \\
(1.19-2.34)\end{array}$ & & \\
\hline $\begin{array}{l}\text { („Perfectionism”) „I work } \\
\text { seriously” }\end{array}$ & $1 \times 10^{-07}$ & $\begin{array}{c}1.38 \\
(1.23-1.56)\end{array}$ & 0.009 & $\begin{array}{c}1.36 \\
(1.08-1.71)\end{array}$ & & & & \\
\hline $\begin{array}{l}\text { („Discontent”) „In life, I had } \\
\text { trouble” }\end{array}$ & $2 \times 10^{-24}$ & $\begin{array}{c}1.89 \\
(1.67-2.14)\end{array}$ & $1 \times 10^{-07}$ & $\begin{array}{c}1.89 \\
(1.49-2.41)\end{array}$ & 0.0008 & $\begin{array}{c}1.81 \\
(1.27-2.58)\end{array}$ & 0.001 & $\begin{array}{c}2.18 \\
(1.35-3.52)\end{array}$ \\
\hline $\begin{array}{l}\text { („Discontent”) „People's } \\
\text { behavior in public places (streets, } \\
\text { institutions, means of transport) } \\
\text { annoys me” }\end{array}$ & $4 \times 10^{-07}$ & $\begin{array}{c}1.36 \\
(1.21-1.53)\end{array}$ & 0.009 & $\begin{array}{c}1.35 \\
(1.08-1.7)\end{array}$ & & & & \\
\hline $\begin{array}{l}\text { (,Discontent") "Life has been } \\
\text { unfair to me" }\end{array}$ & $2 \times 10^{-11}$ & $\begin{array}{c}1.5 \\
(1.34-1.69)\end{array}$ & 0.003 & $\begin{array}{c}1.41 \\
(1.12-1.77)\end{array}$ & 0.005 & $\begin{array}{c}1.62 \\
(1.16-2.28)\end{array}$ & 0.01 & $\begin{array}{c}1.78 \\
(1.14-2.78)\end{array}$ \\
\hline
\end{tabular}

In the parentheses, preceding each psychological item, there is the psychological category which includes the item; (G-3M-group/G-6M-group/G-12M-group/G-group = the group of patients with ultrasonographic evidence of gallstones in the last 3 months/in the last 6 months/in the last 12 months/any time in the past; $E+D+/ E+D-=$ number of exposed patients with/without gallstones;

$E-D+/ E-D-=$ number of non-exposed patients with/without gallstones; OR = odds ratio; $95 \% \mathrm{Cl}=95 \% \mathrm{confidence} \mathrm{interval;} P=P$-value.

Not only are all Psylts in the ,Sacrifice” PsyCt ASS-C_G, but this PsyCt also has a high internal consistency $(\mathrm{CrA}=0.89)$ and synergy $(\mathrm{CrA}$ for the group is definitely higher than the CrA for all the one-item less partial subgroups, which are 0.875 , $0.862,0.868,0.859$, and 0.869 , respectively).

The ASS-C_G PsyIts in the "Responsibility” PsyCt add up into a low CrA (0.575) group (internally synergic: $0.495,0.568$, and 0.321 , respectively), but they are part of a much bigger, internally consistent $(\mathrm{CrA}=0.798)$ and synergic 13-Psylts group.

The same applies to the "Commitment" PsyCt, with the three PsyIts ASS-C_G (Table 3) forming a group with a low $\mathrm{CrA}(0.575)$, although internally synergic $(0.542,0.446$, and 0.464 , respectively). Nevertheless, they are part of a larger 10-PsyIts group with good internal consistency $(\mathrm{CrA}=0.829)$ and synergy.

\section{DISCUSSION}

The PsyIts ASS-C_G fall in several PsyCts that can be circumscribed to several psychic tendencies. One is the concern for others' well-being, which seems to be the defining psychological feature for gallstone patients, as indicated by the PsyIts in „Compassion”, „Sacrifice”, and „Altruism” PsyCts (Table 3). Nonetheless, there is a second psychic tendency delineated by PsyIts in „Order”, „Equity” (Table 1), „Profession preoccupation” (notice the subunitary OR), „Perfectionism”, „Authority”, „Authoritarian parents” (Table 2), and „Responsibility" (Table 3) PsyCts, that have in common the compliance with something imposed: order, rules, norms. It has been shown that perfectionsim and perfectionistic self-presentation, which relate to our PsyCts "Profession preocupation", were associated with greater sickness impact in ulcerative 
TABLE 5. The Psylts in the fourth domain absolutely or relatively significantly correlated with at least two of the four gallstone groups.

\begin{tabular}{|c|c|c|c|c|c|c|c|c|}
\hline \multirow[b]{2}{*}{ Psylt } & \multicolumn{2}{|c|}{ G-group } & \multicolumn{2}{|c|}{ G-12M-group } & \multicolumn{2}{|c|}{ G-6M-group } & \multicolumn{2}{|c|}{ G-3M-group } \\
\hline & $\boldsymbol{P}$ & $\begin{array}{c}\text { OR } \\
(95 \% \mathrm{Cl})\end{array}$ & $P$ & $\begin{array}{c}\text { OR } \\
(95 \% \mathrm{Cl})\end{array}$ & $\boldsymbol{P}$ & $\begin{array}{c}\text { OR } \\
(95 \% \mathrm{Cl})\end{array}$ & $P$ & $\begin{array}{c}\text { OR } \\
(95 \% \mathrm{Cl})\end{array}$ \\
\hline $\begin{array}{l}\text { („Compassion") „I worry for my } \\
\text { colleagues or neighbors, even if we } \\
\text { are not close to each other" }\end{array}$ & $3 \times 10^{-09}$ & $\begin{array}{c}1.43 \\
(1.27-1.62)\end{array}$ & 0.02 & $\begin{array}{c}1.3 \\
(1.03-1.64)\end{array}$ & & & & \\
\hline $\begin{array}{l}\text { („,Compassion”) „I worry for my } \\
\text { family members" }\end{array}$ & $6 \times 10^{-12}$ & $\begin{array}{c}1.52 \\
(1.35-1.71) \\
\end{array}$ & 0.002 & $\begin{array}{c}1.43 \\
(1.13-1.79) \\
\end{array}$ & & & & \\
\hline $\begin{array}{l}\text { („Compassion”) „I worry about } \\
\text { strangers if I know they are in a } \\
\text { difficult situation” }\end{array}$ & $1 \times 10^{-08}$ & $\begin{array}{c}1.45 \\
(1.28-1.65)\end{array}$ & 0.008 & $\begin{array}{c}1.4 \\
(1.09-1.8)\end{array}$ & & & & \\
\hline $\begin{array}{l}\text { („Compassion") „It affects me when } \\
\text { someone is suffering/ has trouble” }\end{array}$ & $3 \times 10^{-16}$ & $\begin{array}{c}1.69 \\
(1.49-1.92) \\
\end{array}$ & 0.002 & $\begin{array}{c}1.48 \\
(1.16-1.88) \\
\end{array}$ & & & & \\
\hline $\begin{array}{l}\text { („,Compassion”) „I feel myself the } \\
\text { distress/ suffering of others" }\end{array}$ & $7 \times 10^{-13}$ & $\begin{array}{c}1.55 \\
(1.37-1.75) \\
\end{array}$ & 0.005 & $\begin{array}{c}1.39 \\
(1.1-1.75) \\
\end{array}$ & 0.0002 & $\begin{array}{c}1.88 \\
(1.35-2.64)\end{array}$ & & \\
\hline $\begin{array}{l}\text { („,Responsibility”) „If I do not fulfill } \\
\text { my civic duties, I feel guilty” }\end{array}$ & $2 \times 10^{-10}$ & $\begin{array}{c}1.56 \\
(1.36-1.79)\end{array}$ & 0.01 & $\begin{array}{c}1.4 \\
(1.07-1.81)\end{array}$ & & & & \\
\hline $\begin{array}{l}\text { („Altruism”) „To feel all right, I do } \\
\text { something for others” }\end{array}$ & $4 \times 10^{-12}$ & $\begin{array}{c}1.55 \\
(1.37-1.75)\end{array}$ & $9 \times 10^{-05}$ & $\begin{array}{c}1.59 \\
(1.26-2.01)\end{array}$ & 0.010363 & $\begin{array}{c}1.57 \\
(1.11-2.21)\end{array}$ & & \\
\hline $\begin{array}{l}\text { („Altruism”) „I do my best for the } \\
\text { comfort of others, even if this makes } \\
\text { me feel uncomfortable” }\end{array}$ & $2 \times 10^{-12}$ & $\begin{array}{c}1.54 \\
(1.36-1.73)\end{array}$ & & & 0.04 & $\begin{array}{c}1.42 \\
(1.01-2)\end{array}$ & 0.02 & $\begin{array}{c}1.67 \\
(1.08-2.6)\end{array}$ \\
\hline $\begin{array}{l}\text { („Altruism”) „I do everything I can } \\
\text { for others” }\end{array}$ & $2 \times 10^{-12}$ & $\begin{array}{c}1.56 \\
(1.38-1.76)\end{array}$ & 0.002 & $\begin{array}{c}1.46 \\
(1.15-1.85)\end{array}$ & 0.005 & $\begin{array}{c}1.66 \\
(1.16-2.37)\end{array}$ & & \\
\hline $\begin{array}{l}\text { („Altruism”) „I neglect my needs in } \\
\text { order to take care of the others" }\end{array}$ & $3 \times 10^{-22}$ & $\begin{array}{c}1.82 \\
(1.61-2.06) \\
\end{array}$ & 0.004 & $\begin{array}{c}1.42 \\
(1.12-1.79) \\
\end{array}$ & 0.01 & $\begin{array}{c}1.57 \\
(1.11-2.22) \\
\end{array}$ & 0.03 & $\begin{array}{c}1.62 \\
(1.04-2.55) \\
\end{array}$ \\
\hline $\begin{array}{l}\text { („,Altruism”) „I sacrifice myself for } \\
\text { others” }\end{array}$ & $2 \times 10^{-16}$ & $\begin{array}{c}1.66 \\
(1.47-1.88) \\
\end{array}$ & 0.0008 & $\begin{array}{c}1.49 \\
(1.18-1.89) \\
\end{array}$ & 0.001 & $\begin{array}{c}1.74 \\
(1.24-2.45) \\
\end{array}$ & 0.01 & $\begin{array}{c}1.77 \\
(1.13-2.76) \\
\end{array}$ \\
\hline $\begin{array}{l}\text { („Altruism”) „I give up my affairs to } \\
\text { help others" }\end{array}$ & $2 \times 10^{-09}$ & $\begin{array}{c}1.47 \\
(1.3-1.67) \\
\end{array}$ & 0.05 & $\begin{array}{c}1.28 \\
(1-1.64)\end{array}$ & & & & \\
\hline („Tension”) „I can stay calm” & $2 \times 10^{-07}$ & $\begin{array}{c}0.72 \\
(0.64-0.82)\end{array}$ & 0.003 & $\begin{array}{c}0.7 \\
(0.55-0.89)\end{array}$ & & & & \\
\hline
\end{tabular}

G-3M-group/G-6M-group/G-12M-group/G-group = the group of patients with ultrasonographic evidence of gallstones in the last 3 months/in the last 6 months/in the last 12 months/any time in the past; $\mathrm{OR}=$ odds ratio; $95 \% \mathrm{Cl}=95 \%$ confidence interval; $\mathrm{P}=\mathrm{P}$-value.

colitis and Crohn's disease (Flett et al., 2011). A study conducted to investigate the causal relationship between personality traits and mortality risk in older adults also incriminated perfectionism and neuroticism as predictors of a significantly greater risk of death compared to individuals in which these personality traits were less evident (Fry and Debats, 2009). These results could easily be extrapolated to our study, as pathologic processes in the digestive tract are somewhat dependent with regards to etiologic agents. Some PsyIts („I am honest even if this puts me at a disadvantage”, „I respect the laws/rules even if it's to my disadvantage") in „Equity” PsyCt (Table 2) suggest a possible link between these two psychic tendencies, indicating a more general one: putting aside one's interests and/ or desires while heeding those of somebody else or of a larger social group. This is epitomized by the PsyIt with the second lowest P (,I neglect my needs in order to take care of the others" in "Sacrifice"
PsyCt - Table 3), which may serve as a beacon in understanding the gallstone psychological profile (in case such a psychological profile does exist). Taking this PsyIt as a focal point, we might identify three psychological continua converging thereto (either deriving from it or abutting to it):

(1) the first goes from the inclination to deny oneself something for the benefit of others (,,Sacrifice") to the broader readiness to do anything for others (,Altruism"), and to the even broader care for/sympathy with others („Compassion”) (Table $3)$;

(2) the second psychological continuum has the same starting point, but runs toward commitment to hard, earnest work: „Work”, „Perfectionism” (Table 2), and „Commitment” (Table 3);

(3) the third may explain our pivotal psychological feature as a consequence of the propensity to heed social/professional rules and principles with the inherent denial of one's immediate needs/ 
TABLE 6. A selection of the PsyCts absolutely or relatively significantly correlated with at least one of the four gallstone groups.

\begin{tabular}{|c|c|c|c|c|c|c|c|c|}
\hline \multirow[b]{2}{*}{ PsyCt } & \multicolumn{2}{|l|}{ G-group } & \multicolumn{2}{|c|}{ G-12M-group } & \multicolumn{2}{|c|}{ G-6M-group } & \multicolumn{2}{|c|}{ G-3M-group } \\
\hline & OR (95\% Cl) & $P$ & OR (95\% Cl) & $P$ & OR (95\% CI) & $P$ & $\begin{array}{c}\text { OR } \\
(95 \% \mathrm{Cl})\end{array}$ & $P$ \\
\hline „Cleanliness" & 1.32 (1.17-1.49) & $6 \times 10^{-6}$ & $1.46(1.16-1.85)$ & 0.001 & & & & \\
\hline „Order” & $1.17(1.04-1.32)$ & 0.008 & & & & & & \\
\hline „Prudence” & $1.24(1.08-1.42)$ & 0.002 & & & $1.61(1.06-2.45)$ & 0.02 & & \\
\hline „Sociability" & & & & & $1.67(1.04-2.7)$ & 0.03 & & \\
\hline „Rumination” & $1.18(1.05-1.33)$ & 0.007 & & & $1.43(1.01-2.01)$ & 0.04 & & \\
\hline „Equity” & $1.44(1.24-1.68)$ & $2 \times 10^{-6}$ & $1.4(1.04-1.88)$ & 0.02 & & & & \\
\hline „Punctuality” & $1.2(1.07-1.35)$ & 0.002 & & & & & & \\
\hline „Work” & $1.68(1.49-1.9)$ & $9 \times 10^{-17}$ & $1.47(1.16-1.86)$ & 0.001 & $1.6(1.13-2.26)$ & 0.007 & $1.57(1-2.47)$ & 0.05 \\
\hline „Demanding profession" & $1.18(1.05-1.33)$ & 0.006 & & & & & & \\
\hline „Patience” & $0.85(0.74-0.97)$ & 0.02 & & & & & & \\
\hline "Contemplative nature" & $1.28(1.13-1.45)$ & 0.0001 & $1.31(1.03-1.67)$ & 0.03 & $1.49(1.04-2.15)$ & 0.03 & & \\
\hline „Authority" & $1.48(1.3-1.68)$ & $5 \times 10^{-9}$ & & & & & & \\
\hline „Endure unacceptable” & $1.29(1.13-1.48)$ & 0.0002 & & & & & 1.63 (1.02-2.61) & 0.04 \\
\hline „Authoritarian parents" & $1.38(1.23-1.56)$ & $9 \times 10^{-8}$ & $1.3(1.04-1.63)$ & 0.02 & & & & \\
\hline „Self-assertion” & $0.77(0.67-0.88)$ & 0.0001 & $0.73(0.56-0.95)$ & 0.02 & & & & \\
\hline „Discontent" & $1.31(1.16-1.48)$ & $9 \times 10^{-6}$ & $1.36(1.08-1.71)$ & 0.008 & $1.4(1-1.96)$ & 0.05 & & \\
\hline „Irritability” & $1.24(1.09-1.4)$ & 0.001 & $1.37(1.08-1.73)$ & 0.009 & $1.74(1.24-2.45)$ & 0.001 & $1.86(1.19-2.9)$ & 0.005 \\
\hline „Openness” & & & $1.27(1.01-1.61)$ & 0.04 & & & & \\
\hline „Compassion” & 1.29 (1.11-1.49) & 0.0008 & & & & & & \\
\hline „Affectionate” & $1.27(1.12-1.43)$ & 0.0001 & $1.46(1.16-1.83)$ & 0.001 & $1.48(1.06-2.08)$ & 0.02 & & \\
\hline „Altruism” & $1.24(1.1-1.4)$ & 0.0004 & $1.43(1.14-1.8)$ & 0.002 & $1.73(1.24-2.43)$ & 0.001 & & \\
\hline „Sacrifice" & $1.7(1.5-1.92)$ & $5 \times 10^{-17}$ & $1.33(1.05-1.68)$ & 0.02 & $1.49(1.05-2.12)$ & 0.02 & & \\
\hline "Responsibility" & $1.18(1.04-1.33)$ & 0.01 & & & & & & \\
\hline „Tension” & $1.17(1.04-1.32)$ & 0.01 & & & & & & \\
\hline
\end{tabular}

The maximal scores for the psychological category (PsyCt) were taken into account; G-3M-group/G-6M-group/G-12M-group/G-group = the group of patients with ultrasonographic evidence of gallstones in the last 3 months/in the last 6 months/in the last 12 months/any time in the past; $\mathrm{OR}=$ odds ratio; $95 \% \mathrm{Cl}=95 \%$ confidence interval; $P=P$-value.

wishes: „Order”, „Equity” (Table 1), „Profession preoccupation”, „Authority”, „Authoritarian parents” (Table 2), „Responsibility” (Table 3);

Putting one's interest on the second place easily (or rather inevitably) becomes a source of frustration and discontent, which is another important psychic tendency in gallstone patients, reflected by the PsyIts in „Discontent” and several PsyCts: „Demanding profession” (Table 2), „Couple, partner”, and „Sense of injustice” (Table 1).

Being tormented by thoughts (,Rumination”Table 1) and a sense of uneasiness/tension (,Tension" - Table 3) are rather expected in such an unsatisfied individual, as a distaste for conflict („Conflict”- Table 1) is in an obedient one.

Caring for and helping others is a normal, positive behaviour, and so are both observing rules/ principles, and applying oneself to work - neither of these should be a source of discomfort. Nonetheless, if in so doing, one tramples on his/her desires, bitterness ensues, which may create a predisposition to GD, as suggested also by animal models (Earley et al., 2004).

Some Psylts that do not fall into the above delineated psychological configuration, such as those in „Health” and „Fear” PsyCts (Table 1). However, the preoccupation with health is hardly surprising in an individual aware of his/her disease, as is the tendency to anxiety and worry, accounting for various fears and phobias. Among these, claustrophobia has the strongest correlation with GD, which may indicate a more specific relation with this disorder, as narrow spaces might be a metaphor for imposed or accepted constraints.

These conclusions concur with those of a previous paper derived from a retrospective study undertaken on a much smaller sample, in which it was proven that organic biliary disorders are more prevalent in submissive, hard-working individuals, prone to discontent and irritability (Dragoş et al., 
2010). By means of that study, we pointed out selfrepression, but we missed self-sacrifice as a characteristic of the psychology of gallstone patients. Nevertheless, we are inclined to consider that the hallmark of a putative gallstone psychological profile is not altruism, but the stifling of one's desires while toiling in the name of external regulations, commands, interests, principles.

The correlations with the PsyCts (Table 6) corroborate the conclusions already reached and warrant some further observations: i) some PsyCts are rather expected in an altruistic person: "Sociability", "Openness", "Affectionate"; ii) the desire for "Cleanliness", "Punctuality", "Patience", a "Contemplative nature", "Prudence", and a reduced inclination to "Self-assertion" (subunitary OR) are understandable in an individual inclined to order, obedience, and self-repression; iii) "Irritability" is quite expected in a disgruntled individual; rather surprisingly, none of the PsyIts pertaining to this PsyCt is ASS-C with any of the gallstone groups, pointing out the generality (and therefore unspecificity) of this PsyCt. For a similar reason (generality and unspecificity), we haven't deem very important the PsyIt most strongly correlated with the G-group: „In life, I had troubles” from „Discontent" PsyCt (Table 2).

Although our study is one of the very few investigating the relationship between the psychological features of individuals and their risk of developing GD, the results would be greatly appreciated by health policy makers and health insurance companies. By means of a simple tool, basically a questionnaire which can be answered on paper or via a web-page by subjects, the risk of developing GD could be predicted in a healthy individual, thus evaluating thoroughly which health insurance plan would be more appropriate. Certainly, such evalua- tion of the risk of developing various diseases for healthy individuals, judging by psychological factors, is not at all only limited to GD, but to a variety of pathologies, as demonstrated by researches in the field of psychocausal medicine, like CVD (Low et al., 2010), irritable bowel disease, gastroduodenal ulcer, etc (Michel and Blanc, 1993). Even though, at present, the questionnaire of our study seems to extensive to be used in surveys concerning the psychological factors predisposing for disease, a shortened, more concise form, that would be quick to apply, would be easily available. In fact, in order to statistically prove the causality between the PsyIts, PsyCts and disease risk, we had to use a battery of 614 items, which in real practice might be reduced to only a few, most significantly correlated with GD risk.

Our study has several limitations. One is the very way we gathered our sample, which was thereby restricted to people that have internet access and are willing to fill in a long questionnaire. Therefore, most of them are young and free from disease (especially from organic disease) and probably less egocentric than the general population (while advertising our study we stated that its aim is to unravel the psychoemotional correlations of diseases). However, it cannot be considered a serious drawback, as it applies to both the subjects and the controls. Another limitation is the cross-sectional nature of the study, which makes it impossible to decide whether the psychoemotional characteristics of the gallstone individuals pre-existed the disease. Nevertheless, common sense suggests that they can hardly be a consequence of the disease. Therefore, as they are associated with the disease, they are most probably linked with the cause of the disease.

\section{REFERENCES}

1. Dragoş D., Ojog D.G., Pănescu O.M., Rusu E.C.,Tănăsescu M.D. (2011) Questionnaire about psychology/disease correlation - I. Journal of Medicine and Life 4(1): 40-56;

2. Dragoş D., Ojog D.G., Tănăsescu M.D. (2011) Questionnaire about psychology/disease correlation - II. Journal of Medicine and Life 4(4): 356-363.

3. Dragoș D., Tănăsescu M.D., Bratu M.M. (2010) A Possible Psychological Profile of Patients with Organic Biliary Affections. Romanian Journal of Medical Practice 5: 115-200.

4. Earley R.L., Blumer L.S. and Grober M.S. (2004) The gall of subordination: changes in gall bladder function associated with social stress. Proceedings of the Royal Society B: Biological Sciences 271(15434): 7-13.

5. Flett G.L., Baricza C., Gupta A., Hewitt P.L., Endler N.S. (2011) Perfectionism, psychosocial impact and coping with irritable bowel disease: a study of patients with Crohn's disease and ulcerative colitis. Journal of Health Psychology 16(4): 561-571.

6. Fry P.S., Debats D.L. (2009) Perfectionism and the five-factor personality traits as predictors of mortality in older adults. Journal of Health Psychology 14(4): 513-524.

7. Geissler P. (1981) Psychosomatic aspects of gallstones. A test psychological study of female gallstone patients with clinical symptoms in comparison with a psychoanalytic study of gallstones. Zeitschrift für Psychosomatische Medizin und Psychoanalyse 27(3): 263-274.

8. Jakovljević M., Reiner Z., Milicić D., Crncević Z. (2010) Comorbidity, multimorbidity and personalized psychosomatic medicine: epigenetics rolling on the horizon. Psychiatria Danubina; 22(2): 184-189. 
9. Khayyam-Nekouei Z., Neshatdoost H., Yousefy A., Sadeghi M., Manshaee G. (2013) Psychological factors and coronary heart disease. ARYA Atherosclerosys 9(1): 102-111.

10. Kuta C., Abbaspour A.,Yim G.K. (1984) Effect of chronic stress on gallstone formation in mice. Pharmacologist 26:187.

11. Lenz H.J., Messmer B., Zimmerman F.G. (1992) Noradrenergic inhibition of canine gallbladder contraction and murine pancreatic secretion during stress by corticotropin-releasing factor. The Journal of Clinical Investigation 89(2): 437-443.

12. Low C.A., Thurston R.C., Matthews K.A. (2010) Psychosocial factors in the development of heart disease in women: current research and future directions. Psychosomatic Medicine 72(9): 842-854.

13. Michel H., Blanc P. (1993) Stress and the digestive system. L'Encéphale 19 Spec No 1: 157-161.
14. Sachdeva S., Khan Z., Ansari M.A., Khalique N., Anees A. (2011) Lifestyle and gallstone disease: Scope for primary prevention. Indian Journal of Community Medicine 36(4): 263-267.

15. Soustek Z., Dyrhonová V. (1981) Etiology and therapy of cholecystitis and cholelithiasis. Zeitschrift für die gesamte innere Medizin und ihre Grenzgebiete 36(21): 824-829.

16. Svebak S., Søndenaa K., Hausken T., Søreide O., Hammar A., Berstad A. (2000) The significance of personality in pain from gallbladder stones. Scandinavian Journal of Gastroenterology 35(7): 759-764.

17. Yousfi S., Matthews G., Amelang M., Schmidt-Rathjens C. (2004) Personality and disease: correlations of multiple trait scores with various illnesses. Journal of Health Psychology 9(5): 627-647. 